\title{
Retraction Note to: ATF3 and Extracellular Matrix-Related Genes Associated with the Process of Chronic Obstructive Pulmonary
}

\author{
Jia Ye ${ }^{1} \cdot$ Li Wen $^{2} \cdot$ De-Ling Liu ${ }^{1}$ Guo-xiang Lai ${ }^{1}$
}

Published online: 17 August 2015

(C) Springer Science+Business Media New York 2015

\section{Retraction Note to: Lung (2014) 192:881-888 \\ DOI 10.1007/s00408-014-9631-4}

The Publisher and Editor retract this article in accordance with the recommendations of the Committee on Publication Ethics (COPE). After a thorough investigation we have strong reason to believe that the peer review process was compromised.

The online version of the original article can be found under doi:10.1007/s00408-014-9631-4.

Guo-xiang Lai

laiguoxiang2007@163.com

1 Department of Respiratory and Critical Care Medicine,

Fuzhou General Hospital of Nanjing Command, PLA,

156 Xihuan Bei Road, Fuzhou 350025, China

2 Department of Anesthesiology, The People's Hospital of Fujian Province, Fujian University of Traditional Chinese Medicine, Fuzhou 350004, China 